\title{
Magnetic Fields Generated By Optical Coupler Circuits May Also Be Containment Loci for Entanglement of P-N Junction-Plasma Cell Membrane Photons Within Exposed Living Systems
}

\author{
Stanley A. Koren ${ }^{1, a}$, W. E. Bosarge ${ }^{2, b}$, Michael A. Persinger ${ }^{1, c}$ \\ ${ }^{1}$ Laurentian University, Sudbury, Ontario, P3E 2C6, Canada \\ ${ }^{2}$ Capital Technologies, Houston, Texas, USA \\ ${ }^{a-c}$ E-mail address: SKoren@laurentian.ca; ed@captech.usa; mpersinger@laurentian.ca
}

\begin{abstract}
The presence of optocouplers, tyristors, Triac switches, and light-emitting diodes within complex electronic circuits that generated magnetic fields within volumes in which living systems are exposed may create the conditions for non-local production of photons within those volumes. Because the power densities of biophotons that mediate inter-cell communication within organisms and potentially control cell proliferation are similar to those for cosmic rays, terrestrial sources of photons, and light emissions during human cognition, this non-locality would involve a field of subtle energies. Calculations show remarkable convergence between current densities and power values within the optocoupler components and the characteristics of photons within conditions that could promote excess correlations and non-locality including the involvement of Casimir forces. Spectral analyses of the computer-generated signals that produced the magnetic field through either the optocoupler or an alternative circuit revealed higher frequency durations in the order of 20 to $40 \mathrm{~ms}$ of "absent signals" that could affect the type of base nucleotide sequencing. The quantitative solutions suggest that under certain conditions the four-dimensional magnetic field within which the animal is exposed during effective treatments of anomalous cell proliferation serves as a dynamic "containment" analogous to a coherent domain where photonic patterns between the electronic equipment and living system are coupled.
\end{abstract}

Keywords: optocouplers; biophotons; magnetic field-photon correspondence; electronic circuits; Casimir energies; excess correlation; intercell communication

\section{INTRODUCTION}

One of the concepts of non-locality or excess correlation over non-traditional distances [1] as well as its most frequent demonstrations depends upon the properties of photons [2-3]. As aptly stated by Vaziri et al [4] photons are likely to be the principle components involved 
with quantum communications. Photons' experimental duality, as a "simultaneous" wave and particle depending upon the form of measurement, would appear superficially to augment the capacity for non-locality in a manner similar to de Broglie's matter waves that would be diffused across maximum space. If the potential for non-locality of photons or their implicit source operates within electronic equipment that employs this energy, then the interpretation of the mechanisms by which this equipment operates and the processes by which magnetic fields generated by these conditions affect biological systems may require modification.

Recently we [5] have found that the applications of weak (nT to $\mu \mathrm{T}$ range), physiologically patterned magnetic fields to animals in which tumors were induced resulted in a remarkable reduction of the size and expression of these malignant processes. The fields were applied in a temporal sequence between opposing pairs of solenoids in the $\mathrm{X}, \mathrm{Y}$, and $\mathrm{Z}$ planes followed by simultaneous generation in all planes (a "4-D" configuration) before the cycle repeated. Measurements indicated the creation of a central focus or "effective zone" within which a homogenous field which displayed. From our perspective the space-time geometry was consistent with the characteristics of a state in which photons might be manifested. This is significant because the effective circuits that generate the magnetic fields involve optocouplers whose presence appears to be essential for the biological effects, particular reduction in tumor cell growths.

Dotta and Persinger [6], employing a similar technology involving photocouplers in the circuit, had found conspicuous excess correlation between amplitudes of photon emissions from two simultaneous hydrogen peroxide-hypochlorite reactions between two separate loci each sharing the same computer-driven circular (rotating) changes in magnetic field vectors. This occurred even though the two reactions were separated by $10 \mathrm{~m}$ or $3 \mathrm{~km}$. The phenomena behaved as if the shared, distal magnetic field conditions resulted in the juxtaposition of the two loci into the same "space". There was a doubling of the nonlocal radiant flux density.

The field strengths $(\sim 2 \mu \mathrm{T})$ we employ are more than a thousand times weaker than those employed by other researchers who have found reductions in tumor growth although their effect sizes are usually of smaller magnitudes. The involvement of optocouplers and LED (light emitting diode) mediated currents within the circuits generating the fields appear to be essential for their efficacy for treatment of three-dimensional masses such as mice. The "4-D" rotational component, that produces forces in each plane sequentially and then all three planes simultaneously may be less important when the fields are applied to two dimensional arrays such as single layers of cancer cells. A picture of this equipment is shown in Figure 1 and was presented as a diagram in McKay et al [7].

Our results have generated a different perspective by which the $\mu$ Tesla intensity magnetic fields might produce the tumor-reducing effects. The model indicates that the generation of the magnetic fields through persistently rotating planes is actually the condition or boundary within which the patterned photon pulses from the custom-constructed equipment are represented within the animal's volume. In most cases the distance between the optocoupler-containing equipment and the solenoids generating the magnetic fields is about 1 to $2 \mathrm{~m}$.

Our operating hypothesis is that within this volume of biological mass the photons generated within the electronic equipment are manifested through non-locality within the central space of the exposure area (effective zone) generated by the three orthogonal arrays of solenoids and modify the intrinsic photons from cytological processes which determine intercellular communication and exchange of information. Here we present quantitative evidence and a potential explanation for these processes. 


\section{BIOPHOTON EMISSIONS AND INTERCELL COMMUNICATIONS}

According to Gurwitsch [8], Popp [9], and Quickenden [10] all living systems from yeast to mammals emit ultraweak intensities of photons. The emissions can be reactive to the antecedent photon stimulation [11] or occur spontaneously when cells are removed from incubation and adjust to room temperature [12]. The typical radiant flux densities are within the range of $10^{-12} \mathrm{~W} \cdot \mathrm{m}^{-2}$ [13] which is an order of magnitude greater than the background for cosmic rays $\left(\sim 10^{-13} \mathrm{~W} \cdot \mathrm{m}^{-2}\right)$ at sea level.

Employing other units, the radiant flux density of biophotons is equivalent to $\sim 10^{-9}$ lux which is similar to the values measured from many distant stars. For comparison the flux density from Sirius is $\sim 10^{-5}$ lux. This magnitude is also within the range of background photon emissions from the earth [14] as well at that associated with cognitive-driven changes in photon emission from the cerebrums of human subjects sitting in hyperdark rooms [15] The photon emissions are particularly high for tumors and cancer cells and can exceed that of other cells by a factor of $10[13,16]$.

The photon emissions are not likely to be metabolic artifacts. Their fluctuations from hippocampal slices [17] are associated with theta activity [18] and to left (intentional) frontal electroencephalographic activity in human subjects [15]. The power density of the photon emissions from human brains engaging in imaginings diminished during ( $\sim 5$ t0 10) nT range increases in geomagnetic activity [19]. A similar relationship was found for luminescent bacteria [20] and cancer cells [21]. The source of the photons has been attributed, by experimental manipulation, to either the nuclear [22] or plasma cell [12,23,] membrane.

Biophoton emissions have been compared to "conversations" with different "dialects" for different types of cells or microbes by Trushin [24]. Biophotons have been shown to be neural communication signals [25]. Dotta et al [26] measured specific shifts in visible wavelengths over a period of several hours from mouse melanoma cells following removal form standard incubation temperatures. The specific wavelengths corresponded to specific changes in different molecular pathways as discerned by application of appropriate agonistic or antagonistic compounds.

Almost 40 years ago Kaznacheev et al [27] showed that the second culture of pairs of healthy tissue cultures, such as chicken embryos, could be contaminated in an adjacent compartment if the other culture was infected with Coxsackie or adeno viruses. This "mirror" cytopathic effect only occurred if the separation between the two compartments was quartz (not thicker than $0.8 \mathrm{~mm}$ ) but not glass. Manifestation of the cytopathic phenomenon required total darkness and rotations of the containers at $\sim 0.4 \mathrm{~Hz}$. Very recently Fels [28] also found that cells separated by glass barriers, particularly quartz, affected each others cell division and energy consumption. He concluded that photon-triggering involved a "fine tuning principle in cell chemistry" and that "organisms or isolated cells can transmit information without the use of a molecular information carrier".

These observations become immediately germane if two loci separated by nontraditional distances share similar electromagnetic field configurations with specific parameters. Dotta and Persinger [6] have demonstrated under these conditions that photonemitting reactions within rotating magnetic fields in two separate loci behave as if they are juxtaposed into the same space. In principle there should be minimal difference between the sharing of photons between two sets of living organisms or a set composed of optocouplercontaining electronic circuitry and the photon flux density within an organism. 


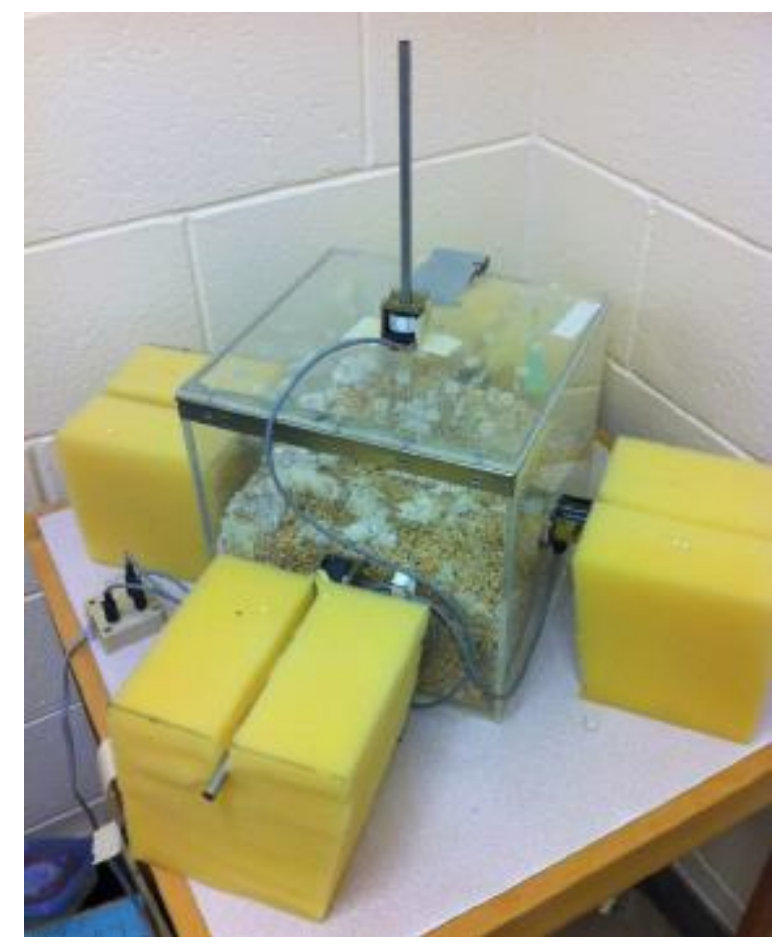

Figure 1. Picture of the "4-D" exposure equipment that generates "spatially" rotating frequency and phase-modulated magnetic fields through successive spatial planes and then in all planes simultaneously that is driven by optocouplers within an electronic circuit.

\section{EQUIPMENT AND CIRCUITRY}

We have developed a relatively unique device (US6312376 Nov 6, 2001; Koren/Persinger; US7553272, June 30, 2009) by which programmable numbers (integers) between 0 and 256 are converted to discrete values between -5 and $+5 \mathrm{~V}$. In this system, the value of 127 is equal to " 0 " polarity. The output from the digital-to-analogue converter (DAC) is delivered as current to the "application geometry" which is an array of solenoids arranged in serial pairs such that the magnetic field is generated between opposing pairs. The duration that each point or voltage is activated, that is the point duration, can be determined by software.

The most optimal point duration is $3 \mathrm{~ms}$ for diminishing malignant cell growth in culture. We [29] have shown that at least six different types of malignant cells (mouse and human) exhibit this inhibition. Point durations that are less, e. g., 1 or $2 \mathrm{~ms}$, or more, e.g., 4 or $5 \mathrm{~ms}$ does not affect cancer cell growth. The growth rates of "normal" or non-malignant cell cultures are not affected by magnetic field patterns employing our usual intensities at any point duration.

A similar specificity of point duration also reduces the growth of experimentally induced melanomas in mice when the fields are applied sequentially in each of the spatial planes $(0.5 \mathrm{~s}$ each) and then simultaneously in all three planes. In this instance the total rotation time for the four phases ( 3 single planes, all three planes) is $2 \mathrm{~s}$ or $0.5 \mathrm{~Hz}$. The exposure duration was nightly for 3 hours within darkness or dim red light. It is relevant that the point duration specificity is also evident for the efficacy of whole body exposures that result in significant analgesia in rodents [30] that was equivalent to $\sim 4 \mathrm{mg} \cdot \mathrm{kg}^{-1}$ of morphine. 
The generation of the fields within the volume within which cells or mice are exposed is produced between two opposed pairs of solenoids which are usually reed relays (Radio Shack, SPST 5VDC 275-0232; nominal current $20 \mathrm{~mA}$; coil resistance $250 \Omega$; contact rating $0.5 \mathrm{~A}$ at $125 \mathrm{VAC}$ ) for smaller exposure volumes such as in Figure 2. For the larger volumes (Figure 1), the "solenoids" are coils (28P-1-24, $24 \mathrm{VDC}, 47.4 \Omega, 506 \mathrm{~mA}$ ) within which metal rods are inserted to enhance the field strength.

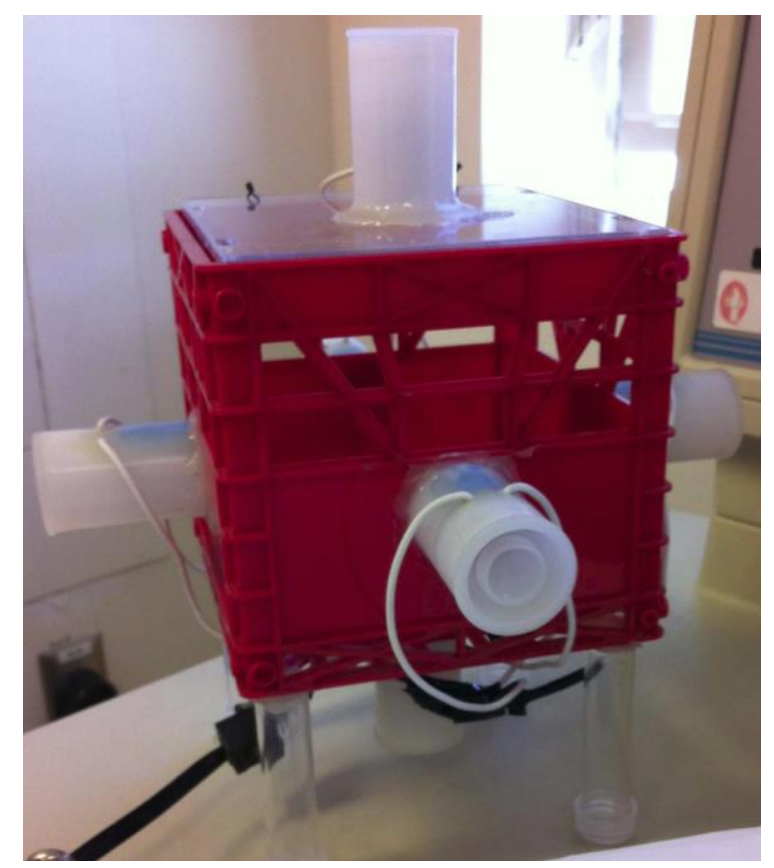

Figure 2. Smaller "4-D" application geometry showing the 3 pairs of solenoids (reed relays) that generate the magnetic fields within each plane successively and then in all planes simultaneously. Malignant cells within the effective zone $(\sim 10.6 \mathrm{~cm}$ diameter $)$ produced by this spatial rotation exhibit dissolution as indicated by their absence. Inside width of box is $14 \mathrm{~cm}$. Note the exposures occur in complete darkness within the incubators.

The strengths of the field within the exposure area vary with the pattern of the field and at $3 \mathrm{~ms}$ point durations range between 2.5 and 3.5 microTesla. Previous calculations [31] have indicated that the optimal intensity for affecting malignant cells, because their hypopolarized resting plasma membrane potential approaches the Nernst equation constant $(\sim 26 \mathrm{mV})$ at standard temperatures is $\sim 2.7 \mu \mathrm{T}$. The value for the Nernst constant is independent of the disparity of ion concentrations between the inside and outside of the membrane. It is related to more cosmological factors coupled to ${ }^{\circ} \mathrm{K}$.

The magnetic field strength was derived from the equivalent energy from that constant applied to the volume of the typical cell [31] within the population being exposed. Under optimal conditions, a cross sectional area (the effective zone) with a diameter of $\sim 10.6 \mathrm{~cm}$ (or about $1 / 2$ of the $21 \mathrm{~cm}$ hydrogen line) with an abrupt demarcation within the middle of the 3-D space is evident where no cells are present although the occasional fragment is discernable by microscopy. The malignant cells outside of this "boundary" proliferate according to their typical profile.

An example of an optimal pattern, a frequency modulated sequence often described as the "Thomas Pulse", is shown in Figure 3. It is composed of 849 numbers each between 0 and 
256 that are converted for $3 \mathrm{~ms}$ (each) to equivalent voltages (between -5 to $+5 \mathrm{~V}$ ). It was developed by Members of this Laboratory and has been shown to be effective as an analgesic for a variety of organisms by Dr. Alex Thomas and his colleagues [32]. This pattern is generated by Complex Software $(C$ created by the first author, where the point duration, time between the presentations of the patterns, and the numbers of repetitions of the patterns are programmed.

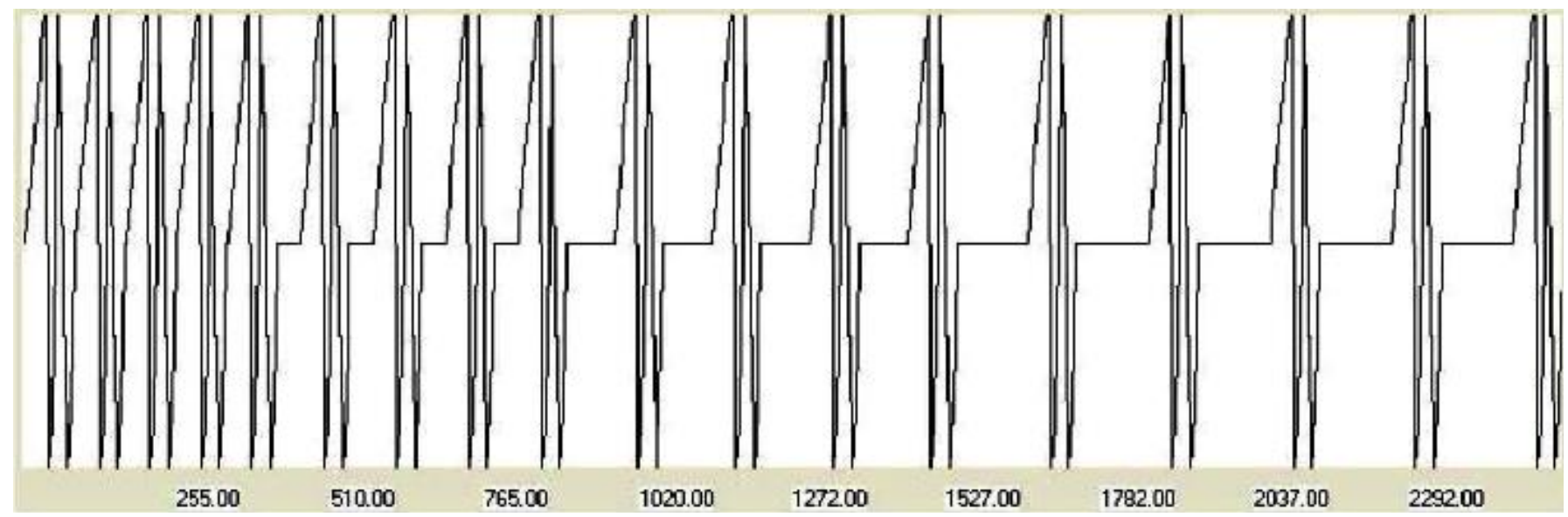

Figure 3. The frequency modulated "Thomas pulse" that when each of the 849 points that compose the shape are presented at $3 \mathrm{~ms}$ slows malignant cells only.

Consequently because there are 849 numbers each presented for the optimal duration of $3 \mathrm{~ms}$, the estimated time for the completion of one sequence of the pattern is $2.547 \mathrm{~s}$. The output from some computers must be modified with a small software program to ensure that 3 ms occurs in real time rather than at processor speed. DOS-based systems are optimal [33]. Window-based computers and related software often generate patterns that are distorted and not biologically effective. The DAC or digital-to-analogue converter transforms the digital programming into analogue values that is processed through the circuitry in Figure 4. Because the transformation of each number into voltage requires computer processing, the port time which is often unique to each computer is critical. Computer port times of between 20 and 25 $\mu$ s or around $40 \mathrm{kHz}$ have been optimal for the computers we have employed.

The Thomas pattern is a frequency-modulated square-like wave with minimal amplitude modulation. Effectively the signal consists of 3 states, 0 or middle, +5 (top) and -5 (bottom). The 3 state signal generation is adapted very effectively to state-of-the-art micro-controller circuitry because the waveform information is contained exclusively in time. However because the semiconductor switch or optocoupler (MOC3010/11/12-IR activated TRIAC) which is an electronic switch influences the signal unusual feedback can occur.

The precision of the $3 \mathrm{~ms}$ value must still be explored with other approaches because our software employs only integer values. Measurements by fast frequency Fourier analyses indicate that the software-circuit interactions that are most effective could actually be within the 3.0 to $3.2 \mathrm{~ms}$ although these values include the port times. We have employed $3 \mathrm{~ms}$ as the optimal point duration to generate the magnetic field patterns based upon our cosmological model derived from Hubble' constant [34]. We have hypothesized that the time required for a classical electron width or proton width to expand one Planck's Length is applicable to this process. 


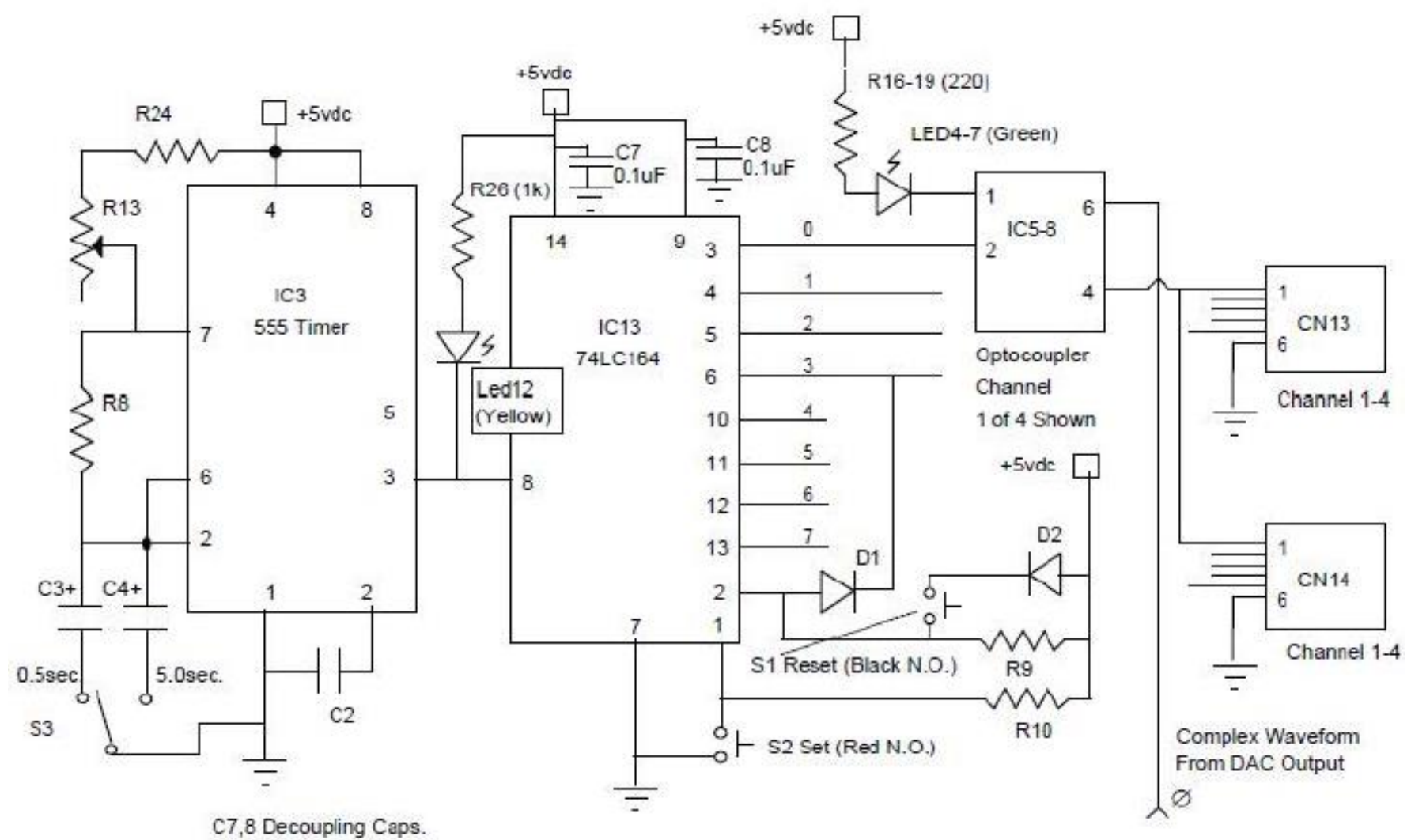

Figure 4. The fundamental circuit (Koren-Persinger US Patent 6312376 Nov 6 2001) by which lines of code generated by numbers between 0 and $256(-5$ to $+5 \mathrm{~V})$ are converted to output that is applied successively through three planes of magnetic fields generated across pairs of solenoids. The point durations of each numerical value, which is optimally $3 \mathrm{~ms}$ for diminishing growth of malignant cells, are modulated through the optocoupler.

If the universal space is expanding we assumed that the units of matter are expanding. Assuming an average value of $\sim 75 \mathrm{~km} \cdot \mathrm{s}^{-1} \cdot$ MParsec where 1 MParsec $=3.1 \cdot 10^{22} \mathrm{~m}$, the parameter is $2.4 \cdot 10^{-18} \mathrm{~s}^{-1}$. The range for the typical 50 to $100 \mathrm{~km} \cdot \mathrm{m}^{-1} \cdot \mathrm{MParsec}^{-1}$ would be between 1.6 and $3.2 \cdot 10^{-18} \mathrm{~s}^{-1}$. The median length of a proton (twice the Compton wavelength or radius) is $\sim 2.6 \cdot 10^{-15} \mathrm{~m}$. For a proton the velocity of this expansion could be considered to be the product of these two values or $6.24 \cdot 10^{-33} \mathrm{~m} \cdot \mathrm{s}^{-1}$. The time required to expand one Planck's length would be that value $\left(1.6 \cdot 10^{-35} \mathrm{~m}\right)$ divided by the velocity or $2.6 \mathrm{~ms}$ with a more likely value with an asymptote around $2.9 \mathrm{~ms}$. Our closest value given the requirement to use only integers in our programming was $3 \mathrm{~ms}$. Additional experiments have indicated that the $3 \mathrm{~ms}$ point duration for excess correlation studies involving photon emissions involved proton-related reactions while point durations of $\sim 1 \mathrm{~ms}$ were more likely to involve electron-related reactions [35].

Although the convergence of $3 \mathrm{~ms}$ point durations with proton-related reactions has salience for cell function because of the relationship between calcium T-channels and their potential coupling to proton channels [36] within the plasma membrane of cells (particularly many cancer cells), the $3 \mathrm{~ms}$ expansion time of one Planck's length for a proton could relate this process to cosmological factors. The involvement of photons from the optocouplers and 
LEDs and the biophotons from the membranes of cells within the organisms exposed to the magnetic fields generated by the equipment could create the conditions for excess correlation.

This possibility increases in likelihood when one appreciates that the average photon density based upon the total numbers of photons from the estimated upper limit of the rest mass of a photon or $\leq 4 \cdot 10^{-52} \mathrm{~kg}$ [37] and the estimated current mass of the universe of $\sim 2 \cdot 10^{52}$ $\mathrm{kg}$ [38] results in $\sim 10^{104}$ photon equivalents. Within a universal volume of $\sim 10^{78} \mathrm{~m}^{3}$, the resulting "density" would be about 1 photon per a volume [39], that is the width of an ion channel $(1 \mathrm{~nm})$. We reasoned there should be quantitative convergence between the essential units of the universe and the conditions created within the optocouplers within the circuit and the internal organization of the magnetic field within which the living systems are exposed.

\section{CALCULATIONS AND NOVEL DERIVATIONS}

Our approach is that the presence of photons through tyristors and triac components creates the conditions for access to cosmological phenomena such as excess correlation (or entanglement) across non-traditional spaces. As a result the exact pattern of photon emissions within the electronic components creating the completion of the circuit that produces the current that supplies the solenoids that generates the magnetic fields occur within a specific boundary of the magnetic field.

These photons emerge within the 4-D space-time (Minkowski space) occupied by the organism exposed within that boundary [40]. The photons produce the inhibition of cell growth through intercell communication rather than the magnetic field, per se. This mechanism could accommodate the criticism and offer an alternative explanation for the contention that Faradic induction from such "weak" electromagnetic fields are too small to produce the marked biochemical changes observed within the cell and organism.

It does not necessarily eliminate the direct contribution of weak magnetic fields with appropriate frequencies to many biochemical effects. The remarkably innovative experiments of Pilla et al [41-43] showed that Larmor precession was a likely mechanism for the biological effects from exposure to weak magnetic fields and could be mediated through ion binding and orientation of bound water molecules. Central components of cell-signaling, such as the modulation of myosin phosphorylation in preparations free of cells exhibited calcium dependence.

The conspicuous bimodal distribution for the reaction velocities for the phosphorylation was dependent upon the kinetics and rate determining molarity of the calcium ion. Dissociation of the calcium ion from calmodulin according to Pilla et al [44] occurs at two different rates $(\mathrm{k})$ equivalent to 10 to $40 \mathrm{~Hz}$ and $300-500 \mathrm{~Hz}$. The two frequencies are assumed to reflect low- and high-affinity sites. This would include both the intrinsic frequency modulation $(\sim 8 \mathrm{~Hz}$ to $\sim 30 \mathrm{~Hz})$ and the point duration $(3 \mathrm{~ms}$ or $333 \mathrm{~Hz})$ of the configuration of the Thomas pattern that has been shown to diminish malignant cell growth most effectively.

One relationship between the flux power density of photon emissions $\left(\mathrm{W} \cdot \mathrm{m}^{-2}\right)$ and magnetic field strength $(\mathrm{T})$ can be derived from dimensional analysis as:

$$
\left[\mathrm{kg} \cdot \mathrm{s}^{-3}\right] \cdot\left[\mathrm{kg} \cdot \mathrm{A}^{-1} \cdot \mathrm{s}^{-2}\right]^{-1}=\mathrm{A} \cdot \mathrm{s}^{-1}
$$

We [45] had established the relationship between background flux power density of photon emissions $\left(\sim 10^{-12} \mathrm{~W} \cdot \mathrm{m}^{-2}\right)$ and $\sim 1 \mathrm{nT}$ geomagnetic fluctuations as measured by a MEDA 
magnetometer placed within $1 \mathrm{~m}$ of a photomultiplier sensor. The resulting relationship is $\sim 10^{-3} \mathrm{~A} \cdot \mathrm{s}^{-1}$ (the actual slope indicated $0.9 \cdot 10^{-3} \mathrm{~A} \cdot \mathrm{s}^{-1}$ ). Stated alternatively the magnetic field strength divided by $1 \mathrm{~mA}$ per second results in the equivalent photon radiant flux density in $\mathrm{W} \cdot \mathrm{m}^{-2}$.

If this ratio can be generalized then the intensity associated with the reduction of malignant tumor growth, about $2.5 \mu \mathrm{T}$, the photon flux density within the opto-couplers and (because of the generation of the specific four-dimensional magnetic field structure) within the animals exposed to the experimental fields would be $\sim 2.5 \cdot 10^{-9} \mathrm{~W} \cdot \mathrm{m}^{-2}$.

Within the area of a cancer cell, assuming a width of $10 \mu \mathrm{m}$, this would approach $2.5 \cdot 10^{-19} \mathrm{~J}$ per s which is within the visible wavelength. Given the range of cell widths in a population the actual range could be between $1000 \mathrm{~nm}(1 \mathrm{um})$ and $450 \mathrm{~nm}$. Hence the light from the photocoupler (which is usually in the near infrared range) would approximate the potential light generated from the cell that is frequently associated with cell communication. Dotta et al [26] found that malignant mouse melanoma cells emit a shifting range of photon wavelengths across this same spectrum after they are removed from standard incubation temperatures $\left(310^{\circ} \mathrm{K}\right)$ and placed at room temperature $\left(295^{\circ} \mathrm{K}\right)$.

The optimal current for the LEDs within the optocoupler employed in the circuit is $15 \cdot 10^{-3} \mathrm{~A}$ and given the unit charge of $1.6 \cdot 10^{-19} \mathrm{~A} \cdot \mathrm{s}$ per $\mathrm{q}$ (charge), there would be $9.3 \cdot 10^{16}$ $\mathrm{q} \cdot \mathrm{s}^{-1}$. Chandra Das and Misra [46] have shown mathematically that a photon could display both positive and negative "charge" corresponding to two spins (clockwise and counterclockwise) whose upper limit would be $\leq 3 \cdot 10^{-33} \mathrm{q}$ (the elementary charge of $1.6 \cdot 10^{-19}$ $\mathrm{A} \cdot \mathrm{s})$ or more specifically $10^{-52} \mathrm{q}(\mathrm{A} \cdot \mathrm{s})$ per photon. We assumed, for parsimony, the most parsimonious atomic interface would be an interaction with the Bohr (magneton) orbital frequency of $6.58 \cdot 10^{15} \mathrm{~s}^{-1}$.

The square of this value $\left(4.3 \cdot 10^{31} \mathrm{~Hz}^{2}\right)$ when multiplied by the photon's charge is $4.3 \cdot 10^{-21} \mathrm{~A} \cdot \mathrm{s}^{-1}$. If there are $3.1 \cdot 10^{16} \mathrm{q} \cdot \mathrm{s}^{-1}$, then the convergence would be $\sim 4.1 \cdot 10^{-4} \mathrm{~A} \cdot \mathrm{s}^{-1}$ $\left(0.4 \cdot 10^{-3} \mathrm{~A} \cdot \mathrm{s}^{-1}\right)$. This value is within a factor of only 2 of the transform between power density and magnetic flux density recorded by our equipment. This predicted value by converting the Chandra Das-Misra photon charge into particle equivalents through the square of the Bohr frequency is within the magnitude of the ratio for background levels of cosmic radiation $\left(10^{-13}\right.$ $\mathrm{W} \cdot \mathrm{m}^{-2}$ ) and $10^{-9} \mathrm{~T}$ fluctuations.

The surface of the optic coupler is $6 \mathrm{~mm} \times 8.5 \mathrm{~mm}$ or $5.1 \cdot 10^{-5} \mathrm{~m}^{2}$ which means that for $12.5 \cdot 10^{-9} \mathrm{~W} \cdot \mathrm{m}^{-2}$ the power is $12.7510^{-14} \mathrm{~J} \cdot \mathrm{s}^{-1}$. The mass equivalent of this energy is almost exactly 1 electron per s or $1.8 \cdot 10^{3}$ electrons per $30 \mathrm{~min}$ of exposure. Within the crosssectional area of the mouse, for example, the energy would be $10^{-12} \mathrm{~W}$, or about a picoJoule per second. If fundamental interactions between molecules such as the sequestering of a ligand to a receptor involve about $10^{-20} \mathrm{~J}$ [47], approximately $10^{8}$ reactions (or most of the chemical reactions in one cell) could be affected per second. A picoJoule is also the energy per second involved with glucose utilization within an average cell.

The optimal current for the LED is $15 \mathrm{~mA}$. However it is connected to a $220 \Omega$ resister in series for fluctuations within the circuit of $5 \mathrm{~V}$. The expected change of voltage across the LED silicon is $0.7 \mathrm{~V}$. The actual resistance is therefore $0.7 \mathrm{~V}$ divided by $15 \mathrm{~mA}$ or $47 \Omega$. It may be relevant that the voltage required to produce the depletion zone (about $1 \mu \mathrm{m}$ or 1000 $\mathrm{nm}$ ) between the two semiconductors is $0.7 \mathrm{~V}$ for Silicon and $0.3 \mathrm{~V}$ for Germanium. The coherent infrared light emitted from GaAs p-n junctions displays a wavelength of 800 to 890 $\mathrm{nm}$ [48]. This is within the range of postulated radiant flux density that would be produced non-locally within the effective zone contained within the magnetic field generated by the circuit. 
Power is the product of the square of the current and the resistance. Hence $2.25 \cdot 10^{-4} \mathrm{~A}^{2}$ $\cdot 4.7 \cdot 10^{1} \Omega$ is $10.6 \cdot 10^{-3} \mathrm{~W}(10.6 \mathrm{~mW})$. The breakdown voltage of air is $3 \cdot 10^{6} \mathrm{~V} \cdot \mathrm{m}^{-1}$ so the space adjusted distance for $0.7 \mathrm{~V}$ is $233 \mathrm{~nm}$. However even small changes in hydration within the gap could alter this discharge threshold. A decrease by a factor of 3 to a unit Megavolt per meter would be associated with a wavelength of $700 \mathrm{~nm}$.

\section{EXCESS CORRELATION ('ENTANGLEMENT') FACTORS}

The convergence with entanglement would occur when the Planck's space velocity for this process is employed in the calculation of energy. Persinger and Koren [49] employed dimensional analyses of geometric products of the boundary conditions of the universe to obtain a "latency" for entanglement that was calculated to be $2.84 \cdot 10^{23} \mathrm{~m} \cdot \mathrm{s}^{-1}$.

The potential validity of this exceptional number was supported by later application of the emerging constant for the product of the formula for a plane, area, and volume of a spherical domain as well as the equivalent frequency which when equated with boundary variables resulted in:

$$
21.3 \pi^{4} \mathrm{r}^{7} \mathrm{f}=\mathrm{G}^{2} \cdot \mathrm{m}^{2} \cdot \mathrm{d} \cdot \mathrm{t}^{2}
$$

where $G$ is the Newtonian Gravitational Constant, $m=$ the mass of the universe, $d=$ diameter of the universe, and $t$ is the age of universe. The seventh root, which would be equivalent to a diffusion term, was $2.84 \cdot 10^{23} \mathrm{~m} \cdot \mathrm{s}^{-1}$. Application of this value to the time involved with relativistic drag of inertial (space-time) frames from direct measurements of satellites and the frequently reported coupling between solar variability and fluid dynamics dependent upon the life-time of the hydronium ion $\left(10^{-12} \mathrm{~s}\right)$ have supported the potential utility of this value [50].

For the present application involvement of excess correlation could be inferred from the energetic solution for the upper limit of the rest mass of a photon which is $\leq 4 \cdot 10^{-52} \mathrm{~kg}$ [37]. When multiplied by the square of the "entanglement" velocity, $8.07 \cdot 10^{46} \mathrm{~m}^{2} \cdot \mathrm{s}^{-2}$, the energy would be $3.23 \cdot 10^{-5} \mathrm{~J}$ per increment. Power requires multiplication by a temporal component $\left(\mathrm{s}^{-1}\right)$.

The optimal increment $(3 \mathrm{~ms})$ for the digital presentation of the change in numberdriven voltages to produce the optimal delay in tumor cell growth is equivalent to $3.3 \cdot 10^{2} \mathrm{~s}^{-1}$. When this frequency is multiplied by the intrinsic energy of the entangled photon the power is $10.7 \mathrm{~mW}$. This is the effective value $(10.6 \mathrm{~mW})$ for the optimal LED and optic coupler values that are associated with successful treatment. Hence the unusual nature of the Triac configuration and optocoupler could allow the conditions for excess correlation to occur.

The role of fundamental forces in the production of the physical conditions that produce the photon field can also be inferred by their congruence with derivations from the Casimir "force" (F):

$$
\pi^{2}(240)^{-1} \cdot \hbar c \cdot\left(a^{-4}\right) \cdot A=F
$$

where $\hbar$ is the modified Planck's constant, $c$ is the velocity of light in a vacuum, a is the separation (in instance the zone created by the breakdown voltage) of $230 \mathrm{~nm}$, and $\mathrm{A}$ is the surface area of the optic coupler $\left(4.98 \cdot 10^{-5} \mathrm{~m}^{2}\right)$. The solution is $2.32 \cdot 10^{-5} \mathrm{~kg} \cdot \mathrm{m}^{-1} \mathrm{~s}^{-2}$ and when applied across the gap of $233 \mathrm{~nm}$ is $5.33 \cdot 10^{-12} \mathrm{~J}$. 
According to traditional treatment the division of this energy by Planck's standard constant results in an energy of $0.8 \cdot 10^{22} \mathrm{~Hz}$ which when divided into the velocity of light results in a wavelength that $3.75 \cdot 10^{-14} \mathrm{~m}$. When the intrinsic expansion constant of space, the second derivative $(8 \pi)$ of the surface area of a sphere is removed (divided) the functional "wavelength" is $1.5 \cdot 10^{-15} \mathrm{~m}$. Although potentially spurious, the value is within measurement error of the classical radius of an electron. A fractional difference in the breakdown voltage of air between the semiconductors or a slight deviation from $0.7 \mathrm{~V}$ would allow complete convergence.

\section{EXPERIMENTAL VISUALIZATION OF OPTOCOUPLER-PATTERN INTERACTIONS: IMPLICATIONS}

The Optocoupler semiconductor Triac Switch that mediates the photon conditions noted in our calculations is shown in Figure 5. Because the wave form information is contained exclusively in time, the influences of avalanche effects become significant. This indicates that the electronic switching of the device could affect the signal and superimpose information relevant to photon amplitude modulation within the organism exposed within the sphere of influence of the magnetic field boundary. Vinal [51] showed that magnetic sensing utilizing an avalanching semiconductor device was practical. He found that a sensitivity equivalent to $30 \mu \mathrm{V} \cdot \mu \mathrm{T}^{-1}$ for $5 \Omega \cdot \mathrm{cm}$ p-type substrate junctions could be discerned. The sensitive area was in the order of $5 \mu \mathrm{m}^{2}$.

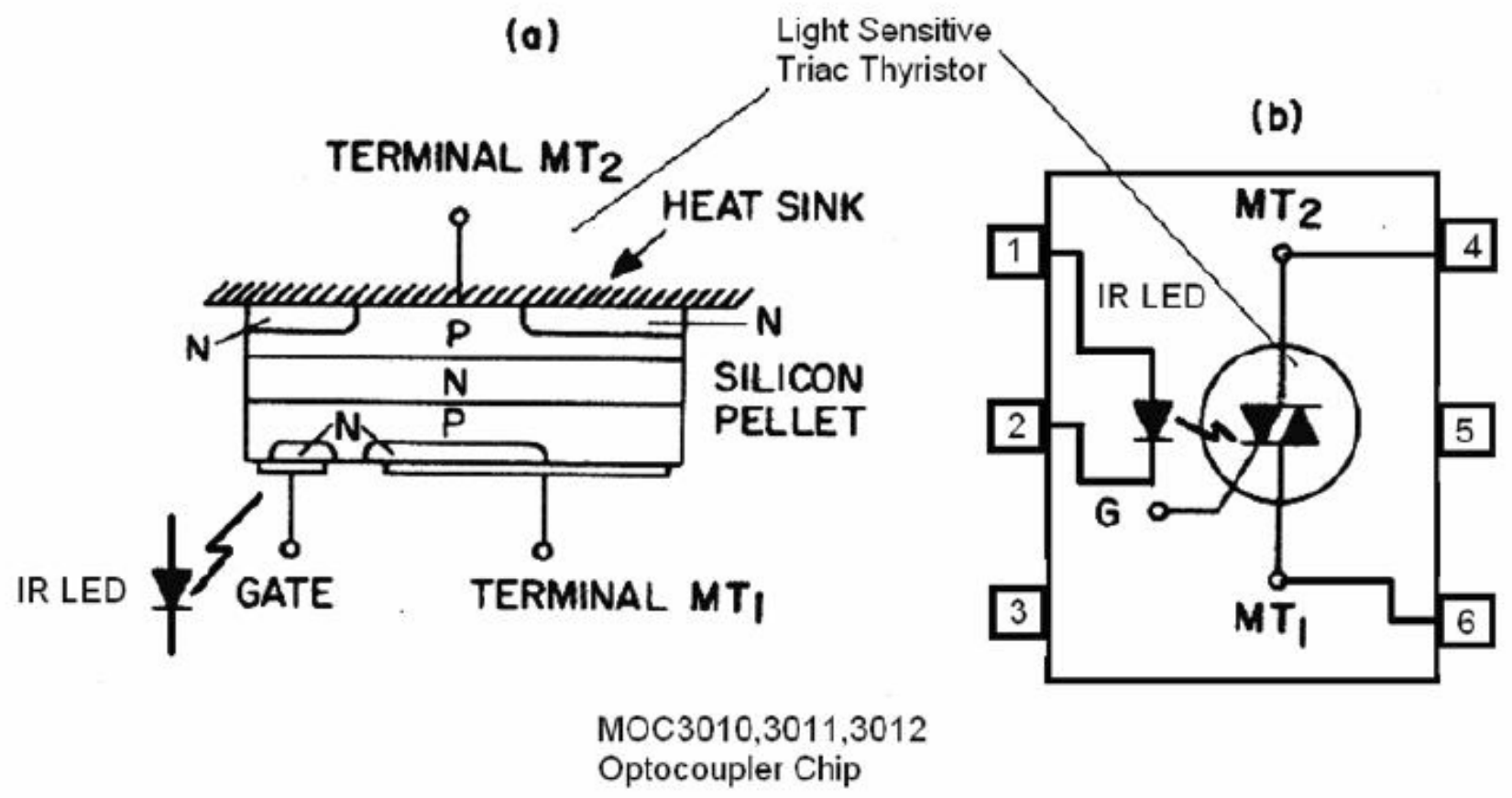

Figure 5. Diagram of the Optocoupler Semiconductor Triac Switch as adapted from manual.

To discern if this could occur, we measured the signal from the DAC with and without the optocoupler feed (Figure 6). Spectral analysis (Spectrogram Version 5.0.1, R. S. Horne, c 1994) of the frequency-modulated (Thomas) pattern was completed with the standard DAC 
circuitry (Figure 6) to compare this direct vs optocoupler input. The upper limit of the spectral frequencies was $10 \mathrm{kHz}$. When the optocouplers were involved with the circuit that generated the magnetic fields there was a clear alteration of the temporal durations at the onset of each pulse. These odd temporal notches were prevalent at $3.6 \mathrm{kHz}$ and evident until about $6 \mathrm{kHz}$. The difference between successive notches at this band was about $400 \mathrm{~Hz}$. We cannot exclude the possibility that the resolution software could not discern the reflection of the point duration or $333 \mathrm{~Hz}$.
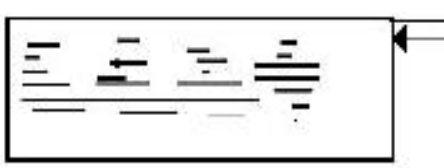

Spectrumn Analyzer

TOP View or Subject with 4 solenolds shown.

ㅁ EMF Induction Coils

$\varnothing$ Main DAC Waveform

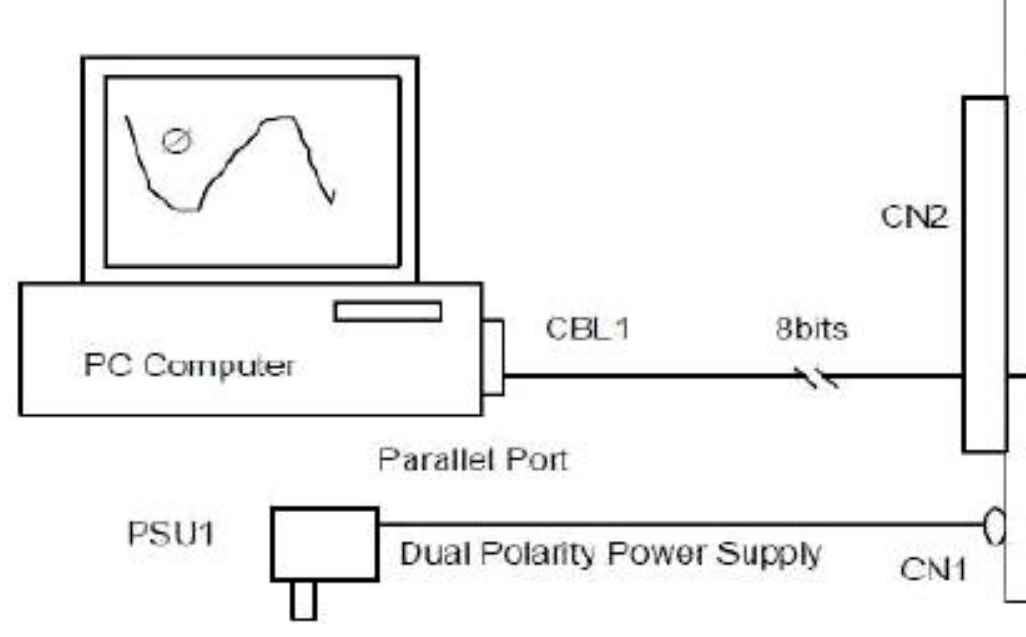

Computer Generates Complex Wayeform (user defined DAC files).

Sequence Timer limes presentation of 4 solenoids independent of Compuler

Direct Coupled

Direct Coupled
solenoid

solenoid

\section{Bit DAC}

DAC4 Interface Unit (BX1)

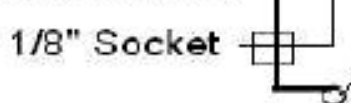

Figure 6. Block diagram of 4 Channel Digital-to-Analogue (DAC) System showing connection for spectral analyses.

This "notch" patterns emerged above $1.5 \mathrm{kHz}$ and were conspicuous in the optocouplergenerated output (Figure 7) compared to the same circuit without involving the optocoupler (Figure 8). We presented the lower part $(<3 \mathrm{kHz})$ of the spectrum discerned by the analyses in these figures (rather than the entire range) so that the notch patterns across the frequency bands were more evident. The top of the figures shows the representation of the pattern. The primary power densities from the photon coupling at various frequencies are indicated by the yellow and darker yellow segments towards the bottom of each figure. As expected given the $3 \mathrm{~ms}$ point durations and the nature of the pattern, most of the energy is within the $<40 \mathrm{~Hz}$ range as indicated towards the bottom of the graphs. 


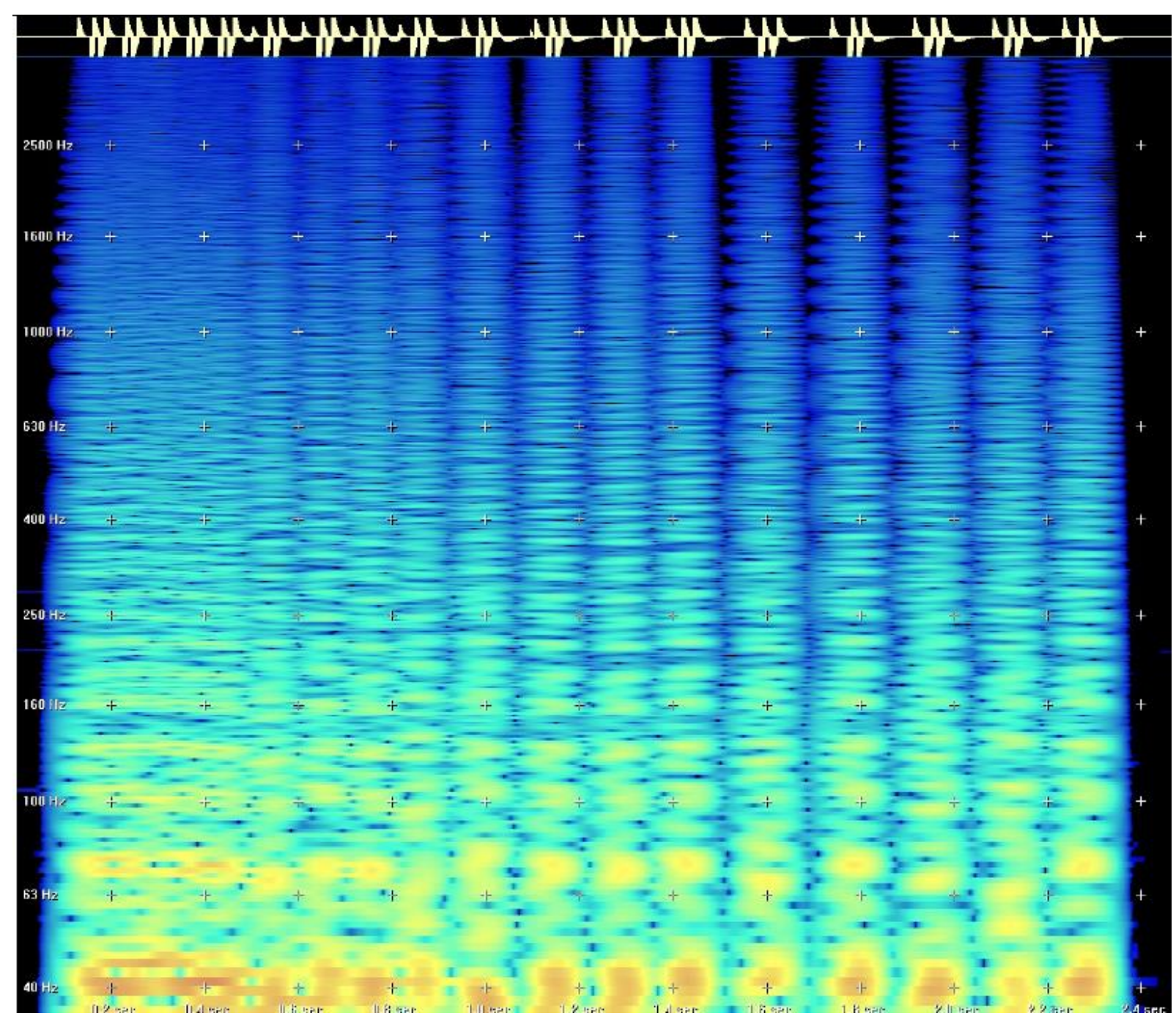

Figure 7. Spectral profile of the signal generated through the optocoupler. The spectral frequency increases up the vertical axis. The horizontal axis refers to time (total $=2.5 \mathrm{~s}$ ). The shape of the pattern is shown along the top. The yellow patches refer to power density which reflects the intrinsic frequency of this pattern with $3 \mathrm{~ms}$ point durations. Note the dark notches or "missing signal time" in the upper half of the graph. The duration is about $30 \mathrm{~ms}$ at frequencies above $1.5 \mathrm{kHz}$ to about $3.6 \mathrm{kHz}$ (not shown) with interfrequency spaces of 150 to $450 \mathrm{~Hz}$.

At the lower frequencies the increments between the successive notches ranged in the order of 150 to $170 \mathrm{~Hz}$. However what was evident and relatively consistent across the entire frequency spectrum was the duration of the "notches" or functionally "no signal". Specific measurements by graphic software indicated that the median durations (or in Figure 7 the extent of invagination into the blue columns) were between 20 and $40 \mathrm{~ms}$.

These results indicate that the inclusion of the optocoupler within the circuit adds complexity across the higher frequency spectrum than when conventional circuits are involved. Hence the interaction between the photons associated with Triac and avalanche positive feedback of the optocoupler and the electrons that comprise the circuit allows the signal and potentially the magnetic field generated within the exposure area to influence the initiating current within the equipment. 


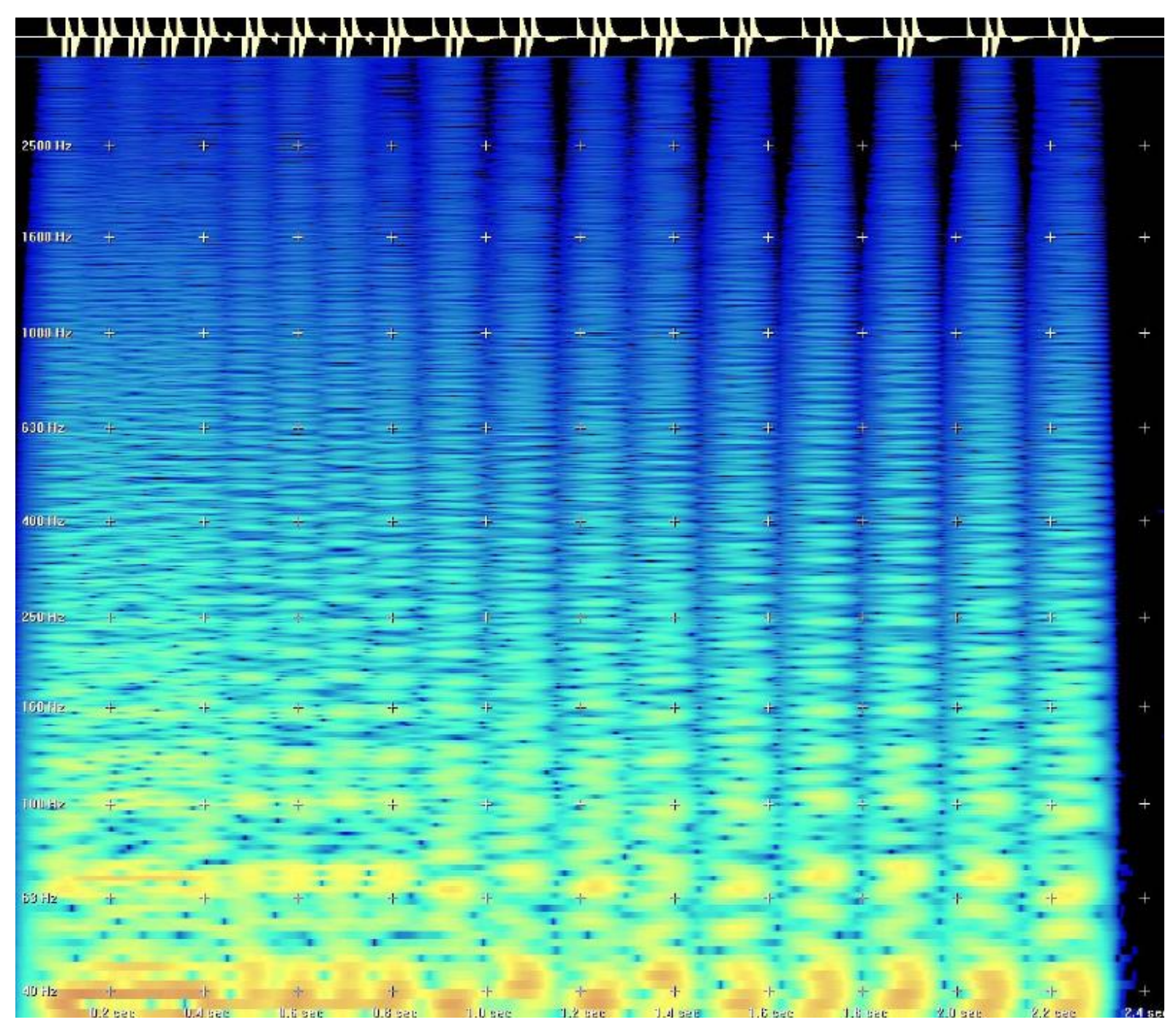

Figure 8. Spectrogram of the same signal as shown in Figure 7 except the optocoupler was not included in the circuit. The output magnetic field strength in the exposure area was identical within the limits of measurement. The primary difference was in the temporal distribution of energies. Note the absence of the notch durations that only occurred with the optocouplers.

There is a 180 degree phase shift between the voltage and the current when an inductive load, such as the circuitry and solenoids associated with the exposure equipment, are involved. The results in depicted in Figure 8 could suggest that there is continuous phasemodulation between the photons generated across the optocoupler and the photons that we are hypothesizing that are manifesting through excess correlation within the sphere of influence within which the cells or animals are exposed.

If the photon fields generated within the optocoupler are modulated within higher frequencies and not limited by the lower frequency substrate that generates the direct magnetic field from the software programming, then the greater potential complexity of information could occur non-locally through the photons that emerge within the effective spherical zone. The direct transfer of higher frequency amplitude modulation of information through photons effectively eliminates the impedance limits and issues of mismatch between circuit and solenoids because the photons carrying faster modulations occur directly by excess 
correlation in the exposed animals. In other words the limits of classical physics due impedance and reluctance factors are circumvented.

The duration of the "notch" or "missing signal time" is within the range of stacking times (20 to $40 \mathrm{~ms}$ ) for base nucleotides during DNA synthesis. The energy associated with such stacking is in the order of $10^{-20} \mathrm{~J}$ and is similar to the energy required to stretch $\left(\sim 10^{-12}\right.$ N) a DNA molecule to $90 \%$ of its contour length over the width of a plasma cell membrane [52]. There is strong experiment evidence that nucleobases display small electron affinities of $\sim 0.1 \mathrm{eV}[53]$. The application of the effects of $1.6 \cdot 10^{-19} \mathrm{~A} \cdot \mathrm{s}$ across a typical resting membrane potential $\left(7 \cdot 10^{-2} \mathrm{~V}\right)$ would be in the order of $1.1 \cdot 10^{-20} \mathrm{~J}$ or $\sim 0.1 \mathrm{eV}[54]$.

Several other researchers have suggested that electron densities generated by narrow bands of oxidative (e.g., cytochrome C) reactions respond to weak magnetic fields [55] and that these fields most likely interact with delocalized $\pi$ electrons in the DNA bases [56]. The threshold intensities for even $60 \mathrm{~Hz}$ sine-wave field effects upon basic reactions are "low". For example, they are 0.2 to $0.3 \mu \mathrm{T}$ for $\mathrm{Na}$,-K-ATPase, $0.8 \mu \mathrm{T}$ to stimulate DNA to initiate protein synthesis, and 0.5 to $0.6 \mu \mathrm{T}$ to stimulate cytochrome oxidase [55].

Hence the production of a specific configuration of 20 to $40 \mathrm{~ms}$ "absent" fields with this specific value for electron volts might affect if a nucleobase would or would not be added. This could potentially alter the critical sequence that bestows unchecked duplicability and division of the cancer cell. This would not occur without the contributing effects from the optocoupler upon the photons with the effective spherical boundary. A similar "quantum" unit has been suggested [57] to accommodate the match between the duration and energy of an action potential with stacking base nucleotides along synthesizing RNA ribbons. It is relevant that intermolecular forces between ligands and receptors (based upon unbinding forces of five different avidin-biotin pairs) was about $85 \pm 10 \cdot 10^{-12} \mathrm{~N}$ [58] or when applied across the plasma cell membrane $\left(10^{-8} \mathrm{~m}\right)$ would be associated with energies $\left(8 \cdot 10^{-19} \mathrm{~J}\right)$ which is in the range of the ultraviolet component $(250 \mathrm{~nm})$ light.

The non-congruence of approximately a factor of 10 between the energy associated with the stacking of nucleobases and the energy associated with the range of visible photons that are measured by photomultiplier devices can be accommodated by the phase modulation. At the median wavelength within the visible spectrum the energy for photons is about $5.5 \cdot 10^{-19} \mathrm{~J}$. Phase modulation by energies equivalent to $10^{-20} \mathrm{~J}$ within the shorter wavelengths would be associated with values in the order of $10 \mathrm{~nm}$, the width of the plasma cell membrane. The chemical reactions within the plasma membrane are the likely origin for a substantial proportion of most biophotons [12].

The width or wavelength of the plasma cell membrane is also the likely locus for the direct interaction between the particulate phase of matter within the cell and the energetic phase from electromagnetic fields and photons. The time required for a photon moving at the velocity of light in a vacuum to traverse the plasma cell membrane of $\sim 10 \mathrm{~nm}$ is $\sim 10^{-16} \mathrm{~s}$. This is within the range of the time required for one orbit of an electron in a hydrogen atom or for the Bohr magneton. The energy derived from the mass equivalent of an electron moving at the fine structure velocity once around this circumference is effectively Planck's constant from which so many quantum calculations and estimates are derived.

In other words, information from photons, presumably originating anywhere, would have the potential to transform into qubits and supraquantum equivalents that could affect the chemical reactions that form and maintain the membrane structure. This structure involves the proteins that define the membrane channels as well as the adjacent internally-interacting cytoskeleton that affects expressions within the nucleus. 


\section{MECHANISMS WITHIN THE (NON-LOCAL) "EFFECTIVE ZONE"}

The manifestation of non-local energy within the effective zone should be significantly affected by the medium that occupies that Minkowskian space. If the mechanisms described are applicable, there should be convergence of quantitative solutions within the properties of this medium and those associated with the processes that occur within the interfaces of the optocoupler of the electronic equipment.

For living organisms the most copious compound within the boundary conditions is water. Its intrinsic concentration is $55 \mathrm{M}$. The molarity of the dynamic hydronium ion $\left(\mathrm{H}_{3} \mathrm{O}^{+}\right)$, which is the source of "free protons" $\left(\mathrm{H}^{+}\right)$, is about $40 \mathrm{nM}$ of the $110 \mathrm{M}$ for the concentration of $\mathrm{H}$ [36]. The life-time of the hydronium ion is $\sim 1 \cdot 10^{-12} \mathrm{~s}(1 \mathrm{ps})$. When a mixture of $30 \%$ protein and $70 \%$ water is involved the associated "rotational motion" can slow to durations of $\sim 12$ ps.

At $\sim 310^{\circ} \mathrm{K}\left(37^{\circ} \mathrm{C}\right)$ water exhibits a viscosity of $6.3 \cdot 10^{-4} \mathrm{~Pa} \cdot \mathrm{s}\left(\mathrm{kg} \cdot \mathrm{m}^{-1} \cdot \mathrm{s}^{-1}\right)$. From one perspective the intrinsic energy within $50 \mathrm{cc}\left(5 \cdot 10^{-5} \mathrm{~m}^{3}\right)$ of water at $1 \mathrm{~Hz}\left(\mathrm{~s}^{-1}\right)$ would be $3.15 \cdot 10^{-8} \mathrm{~J}$. The temporal component $(\mathrm{Hz})$ is important because the wave form information generated by the DAC equipment is contained exclusively in time. The energy associated with proton mobility is about $1.9 \cdot 10^{-20} \mathrm{~J}$ [36]. Consequently there would be sufficient energy for $2.6 \cdot 10^{12}$ reactions. If the frequency was $333 \mathrm{~Hz}$ (the point duration, $3 \mathrm{~ms}$ and the time required for a proton to expand one Planck's distance) and hence $1.1 \cdot 10^{-5} \mathrm{~J}$, the numbers of potential reactions would be $8.6 \cdot 10^{14}$. Assuming $10^{-12} \mathrm{~s}$ for the duration of a hydronium ion, this energy intrinsic energy from an applied oscillation would be sufficient to influence between 1 and 100 "continuous" Grotthuss sequences within that volume per second.

Within an aqueous volume of $50 \mathrm{cc}$ at $\mathrm{pH} 6.0$ there would be $\sim 1.63 \cdot 10^{18} \mathrm{H}^{+}\left(\mathrm{M}=10^{-\mathrm{pH}}\right.$ $\cdot 6.023 \cdot 10^{23}$ units per $\mathrm{M}$ multiplied by $2.7 \mathrm{M}$ within $50 \mathrm{cc}$ ). For a $\mathrm{pH}$ of 8.0 , the value would be $1.6 \cdot 10^{16} \mathrm{H}^{+}$. For these numbers of $\mathrm{H}^{+}$reactions to be influenced by $8.6 \cdot 10^{14}$ reactions per implicit second between $\sim 30 \mathrm{~min}$ and $20 \mathrm{~s}$ would be required. The former is the empiricallybased minimum exposure time required to produce discernable effects upon $\mathrm{Ca}^{2+}$ influx and diminished growth in malignant cells [29] which occurs conspicuously when the media $\mathrm{pH}$ ( 6.6) is more acidic. This type of relationship reiterates the importance of the volume of the water to be affected as well as the $\mathrm{pH}$ with respect to the magneto-optic effects we have described. It is illustrative that at an intercellular $\mathrm{pH}$ of 6 there are approximately $3.15 \cdot 10^{5}$ free protons in an entire cell [36].

If one cell was affected and generated a different photon pattern through intercellular transmission the entire population of cells sharing the same "dialect" [24] the entire aggregate could be affected. We [26] have shown that the likely reflection of cancer cell-generated photons in the order of $10^{-12} \mathrm{~W} \cdot \mathrm{m}^{-2}$ from the mirrors that constitute the $10 \mathrm{~nm}$-specific wavelength filters within the visible range inhibited their own population growth. That changing the activity of only one cell can ultimately affect the activity of an entire population composed of tens of millions of cells has been shown clearly for neurons [59].

The calculations above reflect gross ranges in $\mathrm{pH}$ and the associated numbers of $\mathrm{H}^{+}$. Exposure of spring water to the same intensity magnetic fields generated by the optocoupler electronic systems employed to affect the cancer cells resulted in shifts of approximately 0.5 to $1 \mathrm{pH}$ units over a few hours [60]. The shifts occurred as successive $\sim 0.02 \mathrm{pH}$ transients with durations in the order of 20 to $40 \mathrm{~ms}$.

A shift of 0.02 units driven by the correlates of the applied magnetic field around $\mathrm{pH}$ 7.4 , a typical value for living cells, would involve $1.67 \cdot 10^{15} \mathrm{H}^{+}$or assuming $10^{-20} \mathrm{~J}$ per reaction about $10^{-5} \mathrm{~J}$, the intrinsic energy within the volume of $50 \mathrm{cc}$ employed in those 
studies [60]. Highstein et al [61] showed that $\mathrm{pH}$ shifts of only 0.2 within a narrow space of approximately $1 \mu \mathrm{m}$ wide with interface separations of $\sim 10 \mathrm{~nm}$, a synapse domain, was sufficient to affect vestibular hair cell activity. The data indicated that protons can behave as neurotransmitters. Considering the numbers of proton channels in plasma cell membranes are $\sim 100$ more than for all other types of channels [36], the demonstration that protons can be "carriers" of information could alter approaches to biomolecular "signaling" pathways.

The physical chemistry of the water molecule is also intricately related to the physical properties coupled to entanglement. Dividing the magnetic moment of the proton $\left(1.41 \cdot 10^{-26}\right.$ $\left.\mathrm{A} \cdot \mathrm{m}^{2}\right)$ by the unit charge $\left(1.6 \cdot 10^{-19} \mathrm{~A} \cdot \mathrm{s}\right)$ results in a term of diffusion $\left(0.88 \cdot 10^{-7} \mathrm{~m}^{2} \cdot \mathrm{s}^{-1}\right)$. When applied to the average viscosity of water the force is $5.5 \cdot 10^{-11} \mathrm{~kg} \cdot \mathrm{m} \cdot \mathrm{s}^{-2}$. This force distributed across the distance of two O-H bonds $\left(1.92 \cdot 10^{-10} \mathrm{~m}\right)$ that would constitute a water molecule results in an intrinsic energy of $\sim 1.1 \cdot 10^{-20} \mathrm{~J}$.

From a cosmological and entanglement perspective this value may be critical. Several different approaches to discern a "fundamental" unit [62] within the universe employing its mass, distance (m) and square of the vacuum fluctuation frequency $\left(\sim 10^{83} \mathrm{~s}^{-2}\right)$ have resulted in estimates of force per unit Planck's Length voxel that when applied across the hydrogen line $(21 \mathrm{~cm})$ results in $10^{-20} \mathrm{~J}$. Such shared values could be argued to be essential for processes that involve non-locality and "entanglement" [63].

More specifically, the treatment of the product of the upper limits of the rest mass of a photon [37] and values for the Lorentz contraction $1 /\left[\sqrt{ }\left[\left(1-\left(\mathrm{v}^{2} \cdot \mathrm{c}^{-2}\right)\right]\right]^{-1}\right.$ when the solution is a negative value as imaginary numbers $(i)$ results in potentially observable energy. Here we assume that $\mathrm{v}$ is the entanglement velocity [49] calculated from universal physical constants and four-dimensional geometry, $2.84 \cdot 10^{23} \mathrm{~m} \cdot \mathrm{s}^{-1}$. For example the product $\leq 4 \cdot 10^{-52} \mathrm{~kg} i$ $\cdot\left(9 \cdot 10^{16} \mathrm{~m}^{2} \cdot \mathrm{s}^{-2}\right) \cdot \sim 10^{15} i$ results in a magnitude that is $10^{-20} \mathrm{~J}$.

One interpretation is that the acceleration of a rest mass photon, the presumed major component to entanglement, through the diffusivity associated with entanglement would emerge as a quantum of energy within the same order of magnitude as that associated with action potential, resting membrane potential, and the force across $\mathrm{O}-\mathrm{H}$ bonds of water. In addition, the magnitude is within measurement error of the values of the second shell hydrogen bonds that have been shown to be a primary factor for the mobility of the proton within water.

The interaction between the geometric properties of the water molecule and the duration of the hydronium ion are revealing [64]. When the typical temporal parameter of $10^{-12} \mathrm{~s}$ is multiplied by the ratio of the proton's magnetic moment and charge $\left(0.88 \cdot 10^{-7} \mathrm{~m}^{2} \cdot \mathrm{s}^{-1}\right)$, the resulting area is $8.8 \cdot 10^{-20} \mathrm{~m}^{2}$ or $2.97 \cdot 10^{-10} \mathrm{~m}(0.296 \mathrm{~nm})$. The actual distance between water molecules is usually measured as $0.29 \mathrm{~nm}$. The convergence of essential physical chemical constants and parameters suggests that the duration of the hydronium ion, that mediates most of the critical physiological effects within cells, organs, and living systems, is coupled to the diffusivity of the dynamics of water.

Over the last few decades several researchers [65-68] have shown theoretically and experimentally that water molecules behave differently near surfaces where exclusion zones emerge. The boundary between these zones of water (whose viscosity can be a factor of 10 greater), and bulk water is occupied by increased densities of protons resulting in electrical potentials that are equivalent to those attributed to the classical ions $\left(\mathrm{K}^{+}, \mathrm{Cl}^{-}\right)$associated with the resting membrane potential. This zone exhibits a peak light absorption of $\sim 270 \mathrm{~nm}$ [69]. For comparison the typical absorption wavelengths for the purines and pyrimidines that compose DNA is $\sim 260 \mathrm{~nm}$. 
Del Guidice and Preparta [70] calculated the parameters within which coherent dynamics of water might control membrane behaviour. They applied the concept of the Dicke Hamiltonian [71,72] whereby below a specific temperature and above a specific atomic density a spontaneous, "Superradiant Phase Transition" emerged. Within this state, classical electromagnetic fields are trapped within the ensemble of atoms oscillating in phase with the atomic transitions between the ground state and a particular excited state. They showed that during the transition phase the size of the coherent domain would be a discrete wavelength that solves within the near UV-visible-near-IR boundary.

They estimated that a typical coherence domain in liquid water would involve values of $\sim 0.26 \mathrm{eV}$ and that the trapped electromagnetic fields within the center of the domain could be as large as $8 \cdot 10^{6} \mathrm{~V} \cdot \mathrm{m}^{-1}$. This is the effective resting potential difference of $80 \mathrm{mV}$ across the width of a plasma membrane of $10 \mathrm{~nm}$. In addition the $0.26 \mathrm{eV}$ would be equivalent to $\sim 10^{-20}$ $\mathrm{J}$, the energy associated with distance between classical proximal plasma membrane ions that have been attributed to the primary source of the resting membrane potential [47].

The dynamics of the Superradiant Phase Transition in a system with a number of twolevel atoms would involve an energy gap of:

$$
\mathrm{E}=\hbar \mathrm{c} \cdot \lambda^{-1}
$$

where $\mathrm{E}$ is the intrinsic energy, $\hbar$ is the modified Planck's constant and $\lambda=$ wavelength. Assuming a unit $10^{-20} \mathrm{~J}$, the wavelength would be $\sim 10^{-6} \mathrm{~m}$ or $\sim 1 \mu \mathrm{m}$. With a coefficient of between 3 and 4 for this unit of energy the resulting wavelength would be within the range of the near infrared light associated with the optocoupler mechanisms [48].

Within the coherence domain molecules vacillate together within a narrow energy band between the tightly bound ground state and an excited state where at least one electron is at the threshold of being "unbound". The vacillation is coupled to the oscillation of the trapped electromagnetic field. The excited state is $12.06 \mathrm{eV}$ greater than the ground state which results in a wavelength of about $100 \mathrm{~nm}$ which is assumed to reflect the diameter of the domain [73, 74].

This approach is consistent with the original ideas developed by N. Bohr who showed that the chemical process associated with $\mathrm{H}_{2--} \geq \mathrm{H}+\mathrm{H}^{+}+e^{-}$is related to a dispersion frequency. There is an emission of energy when two hydrogen atoms combine or the absorption of energy when a hydrogen molecule dissociates. The frequency of the energy absorbed is $\sim 3.6 \cdot 10^{15} \mathrm{~Hz}$. Assuming the velocity of $\mathrm{c}$ in a vacuum, the wavelength is $\sim 83 \mathrm{~nm}$. Since the early $20^{\text {th }}$ century quanta of energy were assumed to be involved with adding or removing an electron. However neither the theory nor the concept indentified the actual source of origin of those electrons.

The estimated power density from equation (1), that is $10^{-9} \mathrm{~W} \cdot \mathrm{m}^{-2}$, when applied to the surface area of the optic coupler could reflect the energy available within the non-local space. The energy would be between $10^{-14}$ and $10^{-13} \mathrm{~J} \cdot \mathrm{s}^{-1}$. Within $1 \mathrm{~s}$ this energy (when divided by $\mathrm{c}^{2}$ ) would oscillate within range of the rest mass of an electron $9.1 \cdot 10^{-31} \mathrm{~kg}$ per s. Within the typical time that produces the cellular effects, between $30 \mathrm{~min}$ and $3 \mathrm{hr}$, this would be equivalent to between $1.8 \cdot 10^{3}$ and $1.8 \cdot 10^{4}$ electrons. These values are within an order of magnitude of the numbers of quasi-free electrons within the coherence domains of water within liquid water $[73,74]$. In other words, the numbers of quasi-free electrons are the same order of magnitude as those that could originate from non-local coupling and the total numbers of free protons in the entire average cell [36]. 


\section{CONCLUSIONS}

The quantitative convergence between the power and flux densities of the photon fields generated within specific complex circuits that involve photon triggering of electric currents to produce magnetic fields and the distal occurrence of these magnetic fields within which an aqueous boundary (such as an organism) is placed suggests an alternative explanation for weak magnetic field effects. The calculations and arguments indicate that the "4-dimensional" magnetic field serves as containment within which non-local manifestations of photons occur at radiant flux densities typical of those that may control cell-to-cell communication. The "entanglement" is consistent with involvement of the upper limits of the rest mass of photons and the involvement of $\sim 10^{-20} \mathrm{~J}$ of energy that mediates its effect through proton movement and electron appearance within $\mathrm{pH}$-dependent water and specific volumes.

\section{References}

[1] A. D. Aczel, Entanglement (2002) Raincoast Books: Vancouver.

[2] B. Julsgaard, A. Kozhekin, E. S. Polzik, Nature 413 (2001) 400-403.

[3] M. Hotta, J. Matsumoto, G. Yusa, Physical Review A 89 (2014) 012311-1-6.

[4] A. Vaziri, G. Weihs, A. Zeilinger, Physical Review Letters 89 (2002) 240401-1-4.

[5] J. H. Hu, L. S. St-Pierre, C. A. Buckner, R. M. Lafrenie, M. A. Persinger, International Journal of Radiation Biology 86 (2010) 79-88.

[6] B. T. Dotta, M. A. Persinger, Journal of Biophysical Chemistry 3 (2012) 72-80.

[7] B. E. McKay, M. A. Persinger, S. A. Koren, Neuroscience Letters 292 (2000) 99-102.

[8] A. A. Gurwitsch, Experientia 44 (1988) 545-549.

[9] F.-A. Popp, Experientia 44 (1988) 543-544.

[10] T. I. Quickenden, S. S. Que Hee, Biochemical and Biophysical Research Communications 60 (1974) 764-770.

[11] R. van Wijk, H. van Aken, Cell Biophysics 18 (1991) 15-29.

[12] B. T. Dotta, C. A. Buckner, D. Cameron, R. M. Lafrenie, M. A. Persinger, General Physiology and Biophysics 30 (2011) 301-309.

[13] B. T. Dotta, R. M. Lafrenie, L. M. Karbowski, M. A. Persinger, General Physiology and Biophysics 33 (2014) 63-73.

[14] M. A. Persinger, G. F. Lafreniere, B. T. Dotta, International Journal of Geosciences 3 (2012) 627-629.

[15] B. T. Dotta, K. S. Saroka, M. A. Persinger, Neuroscience Letters 513 (2012) 151-154.

[16] R. van Wijk, J. M. van Aken, Experientia 48 (1992) 1092-1102.

[17] Y. Isojima, T. Isoshima, K. Nagai, K. Kikuchi, H. Nakagawa, NeuroReport 6 (1995) 658-660.

[18] Y. Kataoka, A. Cui, M. Yamagata, T. Niigaki, N. Hirohata, Y. Oishi, Biochemical and Biophysical Research Communications 285 (2001) 1007-1001. 
[19] M. A. Persinger, B. T. Dotta, K. S. Saroka, M. A. Scott, Journal of Consciousness Exploration \& Research 4 (2103) 1-24.

[20] L. Yu. Berzhanskaya, O. Yu. Beloplotova, V. N. Berzhansky, IEEE Transactions of Magnetics 31 (1995) 4274-4275.

[21] B. T. Dotta, C. A. Buckner, R. M. Lafrenie, M. A. Persinger, Brain Research 388 (2011) 77-88.

[22] R. Q. Scott, P. Roschger, B. Devaraj, H. Inaba, Federation of European Biochemical Societies 285 (1991) 97-98.

[23] R. Vogel, R. Suessmuth, Biochemistry and Bioenergetics 45 (1998) 93-101.

[24] M. V. Trushin, Microbiological Research 159 (2004) 1-10.

[25] Y. Sun, C. Wang, J. Dai, Photochemical \& Photobiological Sciences 2010.

[26] B. T. Dotta, N. J. Murugan, L. M. Karbowski, R. M. Lafrenie, M. A. Persinger, Naturwissenschaften 101 (2104) 87-94.

[27] V. P. Kaznacheev, S. P. Shurin, L. P. Mikhailova, N. V. Ignatovish, Psychoenergetic Systems 1 (1976) 141-142.

[28] D. Fels, PLos ONE 4 (2009) e5086.

[29] C. Buckner, Effects of Electromagnetic Fields on Biological Processes are Spatial and Temporal Dependent (2011) Ph.D. Thesis, Laurentian University: Sudbury (Canada).

[30] L.J. Martin, S. A. Koren, M. A. Persinger, Pharmacology, Biochemistry and Behavior 78 (2004) 217-227.

[31] M. A. Persinger, R. M. Lafrenie, International Letters of Chemistry, Physics and Astronomy 17 (2014) 67-77.

[32] A. W. Thomas, M. Kavaliers, F. S. Prato, K-P. Ossenkopp, Peptides 19 (2000) 333-342.

[33] M. A. Persinger, in M. J. McLean, S. Engstrom, R. R. Holocomb (eds), Magnetotherapy: Potential Therapeutic Benefits and Adverse Effects (2003) New York, TFG Press, pp. 89-118.

[34] M. A. Persinger, S. A. Koren, International Journal of Neuroscience 117 (2007) 157-175.

[35] S. A. Koren, B. T. Dotta, M. A. Persinger, The Open Astronomy Journal 7 (2014) 1-6.

[36] T. E. DeCoursey, Physiological Review 83 (2003) 475-579.

[37] L-C. Tu, J. Luo, G. T. Gilles, Reports on Progress in Physics 68 (2005) 77-130.

[38] M. A. Persinger, International Letters of Chemistry, Physics and Astronomy 8 (2013) 8-19.

[39] M. A. Persinger, International Letters of Chemistry, Physics and Astronomy 11 (2014) 59-66.

[40] M. A. Persinger, Neuroscience and Biobehavioral Reviews 36 (2012) 2334-2338.

[41] A. A. Pilla, Annals of the New York Academy of Science 238 (1974) 149.

[42] M. S. Markov, A. A. Pilla, Bioelectrochemistry and Bioenergetics 43 (1997) 235-239. 
[43] A. A. Pilla, D. J. Muehsam, M. S. Markov, Biochemistry and Bioenergetics 43 (1997) 241-249.

[44] A. A. Pilla, D. J. Muehsam, M. S. Markov, B. F. Sisken, Bioelectrochemistry and Bioenergetics 48 (1999) 27-34.

[45] D. Vares, M. A. Persinger, Journal of Non-Locality II(2) (2013)

[46] M. Chandra Das, R. Misra, International Journal of Astronomy and Astrophysics 2 (2012) 97-100.

[47] M. A. Persinger, Current Medicinal Chemistry 17 (2010) 3094-3098

[48] R. N. Hall, G. E. Fenner, J. D. Kingsley, T. J. Soltys, R. O. Carison, Physical Review Letters 9 (1962) 366-369.

[49] M. A. Persinger, S. A. Koren, The Open Astronomy Journal 6 (2013) 10-13.

[50] M. A. Persinger, S. A. Koren, International Letters of Chemistry, Physics and Astronomy 15 (2014) 80-86.

[51] A. W. Vinal, IBM Journal of Research Development 23 (1981) 196-201.

[52] P. Cluzel, A. Lebrun, C. Heller, R. Lavery, J-L. Viovy, D. Chatenay, F. Caron, Science 271 (1996) 792-794.

[53] J. Gu, Y. Xie, H. F. Schaefer III, Nucleic Acids Research 35 (2007) 5165-5172.

[54] M. A. Persinger, International Letters of Chemistry, Physics and Astronomy 2 (2014) $15-21$.

[55] M. Blank, L. Soo, Bioelectrochemistry and Bioenergetics 45 (1998) 253-259.

[56] M. Blank, R. Goodman, International Journal of Radiation Biology 87 (2011) 409-415.

[57] L. Y. Wei, Bulletin of Mathematical Biophysics 31 (1969) 39-58.

[58] V. T. Moy, E-L. Florin, H. E. Gaub, Science 266 (1994) 257-259.

[59] C-y. T. Li, M-m. Poo, Y. Dan, Science 324 (2009) 643-645.

[60] N. J. Murugan, L. M. Karbowski, M. A. Persinger, Water 6 (2014) 45-60.

[61] S. M. Highstein, G. R. Holstein, M. A. Mann, R. D. Rabbitt, PNAS (2014) doi/10.1073.1319561111.

[62] M. A. Persinger, S. A. Koren, G. F. Lafreniere, NeuroQuantology 6 (2008) 262-271.

[63] S. A. Koren, M. A. Persinger, Journal of Physics, Astrophysics and Physical Cosmology 4 (2010) 1-4.

[64] M. A. Persinger, International Letters of Chemistry, Physics and Astronomy 2(2014) 1-10.

[65] G. H. Pollack, X. Figueroa, Q. Zhao, International Journal of Molecular Sciences 10 (2009) 1419-1429.

[66] J. DeMeo, Water 3 (2011) 1-47.

[67] V. L. Voeikov, E. Del Giudice, Water 1 (2009) 52-75.

[68] E. Del Giudice, P. R. Spinetti, A. Tedeschi, Water 2 (2010) 566-586. 
[69] J-m. Zheng, W-C. Chin, E Khijniak, E. Khijniak Jr, G. H. Pollack, Advances in Colloid and Interface Science 127 (2006) 19-27.

[70] E. Del Giudice, G. Preparata, Journal of Biological Physics 20 (1994) 105-116.

[71] B. M. Garraway, Philosophical Transactions of the Royal Society A 369 (2011) 1137-1155.

[72] T. C-Y. Liu, S-H Liu, F. A. Popp, A-Q. Tang, SPEI 2887 (2009) 162-168.

[73] R. Arani, I. Bono, E. Del Guidice, G. Preparata, International Journal of Modern Physics B 9 (1995) 1813-1841.

[74] R. Bajapi, L. Brizhik, E. Del Giudice, F. Finelli, F-A. Popp, K-P. Schlebusch, Journal of Acupuncture Meridian Studies 3 (2010) 291-297. 